\title{
Documenting the Individual- and Household-Level Cost of Unsafe Abortion in Uganda
}

\author{
By Aparna \\ Sundaram, \\ Michael Vlassoff, \\ Frederick \\ Mugisha, \\ Akinrinola \\ Bankole, \\ Susheela Singh, \\ Leo Amanya and \\ Tsuyoshi Onda
}

Aparna Sundaram and Michael Vlassoff

are senior research

associates; Akinrinola

Bankole is director

of international re-

search; Susheela Singh

is vice president for

research; and Tsuyoshi

Onda is research

assistant-all at the

Guttmacher Institute,

New York. Frederick

Mugisha and Leo

Amanya are independent researchers, Kampala, Uganda.

\begin{abstract}
CONTEXT: Although Uganda has a restrictive abortion law, illegal abortions performed under dangerous conditions are common. Data are lacking, however, on the economic impact of postabortion complications on women and their households.
\end{abstract}

\begin{abstract}
METHODS: Data from a 2011-2012 survey of 1,338 women who received postabortion care at 27 Ugandan health facilities were used to assess the economic consequences of unsafe abortion and subsequent treatment. Information was obtained on treatment costs and on the impact of abortion complications on children in the household, on the productivity of the respondent and other household members, and on changes in their economic circumstances.
\end{abstract}

RESULTS: Most women reported that their unsafe abortion had had one or more adverse effects, including loss of productivity (73\%), negative consequences for their children (60\%) and deterioration in economic circumstances (34\%). Women who had spent one or more nights in a facility receiving postabortion care were more likely than those who had not needed an overnight stay to experience these three consequences (odds ratios, 1.6-2.8), and women who had incurred higher postabortion care expenses were more likely than those with lower expenses to report deterioration in economic circumstances (1.6). Wealthier women were less likely than the poorest women to report that their children had suffered negative consequences (0.4-0.5).

CONCLUSIONS: The impact of complications of unsafe abortion and the expense of treating them are substantial for Ugandan women and their households. Strategies to reduce the number of unsafe procedures, such as by expanding access to contraceptives to prevent unintended pregnancies, are urgently needed.

International Perspectives on Sexual and Reproductive Health, 2013, 39(4):174-184, doi: 10.1363/3917413

Induced abortion is common in Uganda. In 2003, the estimated rate was 54 abortions per 1,000 women aged 15-49; although the rate may have changed somewhat since then, it is nonetheless likely among the highest in the world. ${ }^{2}$ Uganda's abortion laws and policies are overall very restrictive, but contain inconsistencies that make it difficult for the medical community and women themselves to understand what is permitted (see Appendix A). As a result, almost all abortions are clandestine, and a large proportion are performed under dangerous conditions. ${ }^{3}$ As a result, unsafe abortion is one of the leading causes of maternal morbidity and mortality in the country. A study carried out in 1993 in three Kampala hospitals found that one in five maternal deaths were attributable to unsafe abortion; ${ }^{4}$ more recently, a 2010 government document estimated that unsafe abortion is the cause of $8 \%$ of maternal deaths. ${ }^{5}$ In 2011, Uganda had a maternal mortality ratio of 438 maternal deaths per 100,000 live births-well above the average of 240 per 100,000 among all developing countries-and unsafe abortion is likely an important contributor to these deaths. ${ }^{6,7}$

Uganda also has a very high unmet need for contraception. The 2011 Uganda Demographic and Health Survey found that $34 \%$ of married women and $35 \%$ of sexually active unmarried women had an unmet need for contraception. ${ }^{6}$ This high level of unmet need leads to a high incidence of unintended pregnancy; the rate of such pregnancies was 141 per 1,000 women aged 15-49 in 2003. ${ }^{1}$ Because of Uganda's restrictive abortion law, many women with unintended pregnancies seek clandestine, unsafe abortions to meet their fertility goals.

One of the consequences of unsafe abortion was documented by a nationally representative survey of health facilities, the results of which suggest that almost 85,000 women in Uganda were treated for complications of unsafe abortions in 2003. ${ }^{1}$ Furthermore, this estimate represents only a portion of the number of women with such complications, as many others do not obtain care at health facilities. The most frequent complications of unsafe abortion are incomplete abortion and hemorrhage; less common but more severe complications include trauma (such as punctures or tearing of the uterus) and sepsis. In addition, some women experience long-term health problems, including chronic pain, pelvic inflammatory disease and infertility. ${ }^{8,9}$ Health complications resulting from unsafe abortion clearly constitute a serious burden for both women and the health care system.

Less well understood, however, is the social and finan- 
cial impact of these complications on the lives of women and their families. Although one could reasonably hypothesize that the cost of treating postabortion complications would have an impact on women and their households, research on the economic consequences of unsafe abortion is scarce, especially in comparison with work on health consequences. A few studies have examined the cost to the health system of treating complications of unsafe abortion. For instance, one study estimated that the annual cost of postabortion care to health systems in Sub-Saharan Africa is about US\$117 million. ${ }^{10}$ Another calculated the annual cost to the Nigerian health system of treating abortion complications to be US\$19 million. ${ }^{11}$ For Uganda, the cost of treating complications of unsafe abortion is estimated to be about US $\$ 14$ million a year. ${ }^{12}$

In addition, a few studies have attempted to estimate the out-of-pocket costs to women of treatment for abortion complications. Henshaw and colleagues found that in Nigeria, women who receive treatment for complications of unsafe abortion pay more for care than do those who are treated for miscarriage (US\$116 vs. US $\$ 43$ ). ${ }^{13}$ Another Nigerian study estimated that the average cost of care for women treated in hospitals for complications of unsafe abortion is US\$132, of which US\$95 (or 72\%) is borne by the woman and her household. ${ }^{11}$ Using Monte Carlo methods, a Ugandan study estimated that the average woman pays US\$62 per abortion in direct costs, including those for any postabortion care. ${ }^{14}$

However, very few studies have looked at the social and economic impact of unsafe abortion on women and their households. A study in Cambodia examined the number of days lost from a woman's normal routine, as well as the wages lost by the woman and her family members because of need for postabortion care and continuing morbidity from the abortion. ${ }^{15}$ Another study, conducted in Thailand, examined women's loss of time and income before, during and after treatment for abortion complications. ${ }^{16} \mathrm{~A}$ review of the literature on abortion costs in Sub-Saharan Africa revealed that very few studies have examined this topic even tangentially. ${ }^{17}$

The lack of data on the economic impact of unsafe abortion is particularly grave in the case of Sub-Saharan Africa, where levels of unsafe abortion ${ }^{2}$ and poverty are high, because the economic shock of out-of-pocket expenditures for unsafe abortion and subsequent care for complications may significantly contribute to the impoverishment of households. We sought to fill this research gap by conducting a survey to measure the costs of unsafe abortion and postabortion care to Ugandan women and their households. We examine these micro-level costs in three ways. First, we measure women's out-of-pocket expenditures for abortion and treatment of postabortion complications. We then study the impact of the complications and associated expenses on the children in the household (if any) and on the productivity of women and other family members. Finally, we examine households' economic responses to the consequences of unsafe abortion: sales of assets, incur- rence of debt, and changes in income and consumption.

Although complications of unsafe abortion also lead to death, we do not examine mortality and its consequences in this article. Mortality is likely to have an even larger impact on women's households than nonfatal complications do, but an entirely different study design would be needed to understand mortality effects.

\section{METHODS}

\section{Data}

We analyzed data from a prospective survey undertaken primarily to achieve the objectives of this article. A total of 1,338 Ugandan women who had been admitted to one of 27 health facilities for treatment of complications of abortion were interviewed while at the facility. Two to three months later, interviewers attempted to obtain follow-up interviews (i.e., they made at least two attempts to contact the respondent to arrange a time and place) with 729 women, of whom 517 completed an interview. * The health facilities were purposively selected to represent Uganda's various regions and levels of health care (Web Appendix Table 1). ${ }^{\dagger}$ The first interviews took place from September 2011 to January 2012, and the follow-up interviews from December 2011 to March 2012. The follow-up interviews were essential because out-of-pocket expenses and lost productivity do not end with the patient's discharge from a health facility. In addition to surveying women, we also interviewed their health care providers to obtain clinical information.

All interviews were administered by nurses and midwives, many of whom were involved in the care of the patients. We reasoned that because they were on the facilities' staff, nurses and midwives would have better access to patients and their health care providers than would external interviewers, and that because they were providers themselves, they would have greater legitimacy in asking women about their health and discussing the sensitive topic of induced abortion. In addition, using facility staff as interviewers allowed us to obtain high response rates to our survey (97\% for women and 100\% for facilities), which offset the potential downsides of using facility staff, such as the interviewers' lack of professional training in economics. Interviewers received five days of training. During data collection, regional supervisors provided guidance to interviewers at facilities within their regions. The central study team members in Kampala coordinated fieldwork, provided support to supervisors and interviewers, and, along with the supervisors, were responsible for quality control.

*The original plan had been to re-interview all women who were classified as likely having had an induced abortion and $50 \%$ of women who were classified as likely having had a spontaneous abortion (see page 182 for classification criteria), but recontacting respondents proved more difficult than anticipated.

†Postabortion care is available in Uganda at public-sector health facilities ranging from national referral hospitals to level III health centers (and at equivalent-level facilities in the private and nongovernmental sectors); services are also available from independent private midwives. 
Interviews were conducted in private rooms at the facilities after the women had completed treatment. All women who received postabortion care at the facility during the data-collection period were presented with a consent form, ${ }^{*}$ and those who agreed to be interviewed and to allow their medical records to be reviewed were recruited into the study. The study received ethical clearance both in Uganda (Makerere University and the Uganda National Council for Science and Technology) and in the United States (Guttmacher Institute).

The questionnaires and instruments used in this study were based on those developed for a 2007 pilot study on the cost of unsafe abortion in Ethiopia, Pakistan and Mexico, which was conducted by a team that included some of the authors of this article. ${ }^{18}$ The first survey collected data on such topics as the amount of money women and their households had spent to obtain an unsafe abortion and postabortion care and the costs of their recuperation. It also collected information on household income, consumption, employment, assets, savings and debt. In addition, women were asked about the economic and productivity costs related to their abortion: their out-of-pocket expenditures, their sources of funds, and the amount of productive time they and other members of their household had lost. The follow-up interviews included similar questions to measure changes in the women's economic circumstances, and also collected information on additional costs incurred after their discharge from health facilities.

Additionally, each woman's principle health care provider was interviewed to obtain information on the nature and severity of her complications, related diagnoses, the treatments she received and her duration of stay at the facility.

\section{Classifying Abortions as Induced or Spontaneous}

Since abortion is legally restricted and heavily stigmatized in Uganda, women typically are reluctant to disclose, especially in an interview, that they have had an abortion. As a result, many women who are being treated for complications say that their abortion was spontaneous (i.e., a miscarriage). Additionally, providers often have difficulty determining whether an abortion was induced or spontaneous, as the symptoms may be very similar. Therefore, in this study, all women being treated for pregnancy loss were interviewed, and information from both the patient and the provider were used to determine the likelihood that the woman's abortion had been induced. We used an algorithm, developed by the World Health Organization (WHO) ${ }^{19}$ that classifies women into four mutually exclusive groups: those who certainly had had an induced abor-

*Consent was obtained by a provider who was not involved in the patient's care.

tOf the 729 women we attempted to interview at follow-up, we classified $35 \%$ as certainly having had an induced abortion, $47 \%$ as probably or possibly having had such an abortion and the remaining $18 \%$ as having had a spontaneous abortions. For the 517 women who completed follow-up interviews, the distribution was $38 \%$ certainly induced abortions, $44 \%$ probable or possible induced abortions and $19 \%$ spontaneous abortions. tion, those who probably had had an induced abortion, those who possibly had had such an abortion and those who likely had had a spontaneous abortion. This allowed us to compare respondents who likely had had unsafe induced abortions with respondents who likely had had miscarriages.

Under this algorithm, a woman was classified as certainly having had an induced abortion if she said she had done something to cause the abortion, if her health provider said she had done so or if the provider found evidence of trauma or of a foreign body in the genital tract. A woman was classified as probably having had an induced abortion if there was evidence of sepsis or peritonitis, and if the pregnancy was unplanned (i.e., she had not been using a method at the time of conception, or she said she had not wanted the pregnancy at all or at that time). If only one of these two conditions applied (e.g., if the woman reported the pregnancy as unplanned, but no sepsis or peritonitis was evident), she was classified as possibly having had an induced abortion. Finally, a woman who did not fit any of these categories was classified as likely having had a spontaneous abortion.

Using this algorithm, we categorized 1,047 women in the full sample (78\%) as likely having had an induced abortion (36\% were classified as certainly, $14 \%$ as probably and $28 \%$ as possibly having had an abortion). We categorized the remaining 291 women (22\%) as likely having had a miscarriage. In the follow-up sample, 420 women (81\%) were classified as certainly, probably or possibly having induced an abortion, and 98 (19\%) as having miscarried. ${ }^{\dagger}$

A comparison of the characteristics of the women who likely had induced an abortion with those who likely had had a miscarriage supports the plausibility of our classifications. Compared with their counterparts in the miscarriage group, women who were classified as having had an induced abortion were significantly more likely to be adolescents, to be unmarried and to be attending school (not shown).

Our analyses focused on the women who likely had had an induced abortion-those who were classified as certainly, probably or possibly having had such an abortion.

\section{Outcome Variables}

We analyzed three types of outcomes to examine the effects of unsafe abortion complications on women and their households. At the first interview, we asked women if their ill health and the expense of trying to induce an abortion had had any impact on their children. In particular, children may have less to eat if the money needed for purchasing food is used instead to pay for medical expenses, or if their mother is too incapacitated to cook for and feed them. Moreover, children may be unable to attend school if their mother's ill health forces them to take on additional responsibilities at home, such as caring for younger siblings; if their mother is too ill to help them get ready for school; or if the school requires fees that the family is unable to pay because of the mother's medical expenses. An abortion was 
considered to have had a negative impact on a woman's children if she reported either of these two outcomes (i.e., the child had less to eat or was unable to attend school).

We also asked women during the first interview if they or someone else in their household was already experiencing loss of productivity as a result of the woman's abortionrelated morbidity. Because the woman's complications were severe enough for her to seek medical help, it is possible that they were preventing her from functioning and working as usual. The complications also could have been affecting the productivity of other adults in the household, who may have been needed at home to take care of the respondent, or to shoulder additional responsibilities that the respondent normally would have taken care of. Thus, our second binary outcome variable was whether the woman or someone else in her household had been unable to work, earn or both.

Our third outcome variable, measured at follow-up, concerned deterioration in women's economic circumstances as a result of their ill health. Because people respond to economic crises in different ways, we used information from multiple questions to construct this variable. Women were classified as having experienced a deterioration in their economic situation if they reported one or more of the following changes between the first and follow-up interviews: loss of economic assets, such as homes, farms or livestock; incurrence of new debt related to treatment expenses; reduction in consumption; or a need for someone in their household to work extra time at their job (to compensate for the woman's loss of income) or to work less time (to accommodate additional responsibilities in the household) in response to the woman's ill health. While the impact of these changes on a household differs, all are evidence of economic deterioration. *

\section{Primary Independent Variables}

- Severity of complications. We used length of stay in a health facility as a proxy for the severity of women's complications, on the assumption that more severe complications require a longer period of stay. ${ }^{\dagger}$ This variable was a more robust measure of severity than a physician's diagnosis, which may be inaccurate or inconsistent, especially in facilities with few resources and poor infrastructure. Checks on our data showed that diagnoses that would typically be considered severe, such as shock, were often associated with shorter lengths of stay in the facility, suggesting that the diagnoses might have been incorrect. The severest complications are likely to have been underreported in our sample, since women with such complications may not have been sufficiently well to be interviewed.

- Medical expenses. We used two variables to measure out-of-pocket expenses incurred by the respondents. The first encompassed expenses for treatment of postabortion complications. Women were asked to provide the amounts spent on transport to the facility; on fees for medical care, tests and medicine; and on food and lodging for themselves and for those who accompanied them.
TABLE 1. Mean out-of-pocket cost (in Ugandan shillings) of abortion and postabortion care, by selected measures, Uganda, 2011-2012

\begin{tabular}{|c|c|c|c|}
\hline Measure & $\begin{array}{l}\text { Abortion attempt } \\
(\mathrm{N}=1,047) \neq\end{array}$ & $\begin{array}{l}\text { Postabortion care } \\
\text { (first interview) } \\
(\mathrm{N}=1,047)\end{array}$ & $\begin{array}{l}\text { Postabortion care } \\
\text { (second interview) } \\
(\mathrm{N}=420)\end{array}$ \\
\hline All & 59,595 & 41,843 & 68,496 \\
\hline \multicolumn{4}{|l|}{ LENGTH OF STAY } \\
\hline 0 (ref) & 67,829 & 28,895 & 48,376 \\
\hline 1 & $50,055^{* *}$ & 29,464 & 44,926 \\
\hline$\geq 2$ & 59,822 & $58,942^{* * *}$ & 92,129 \\
\hline \multicolumn{4}{|l|}{$\begin{array}{l}\text { FACILITY CHARACTERISTICS§ } \\
\text { Ownership }\end{array}$} \\
\hline Public & na & $32,267^{* * *}$ & na \\
\hline Private/NGO (ref) & na & 153,838 & na \\
\hline \multicolumn{4}{|l|}{ Type } \\
\hline Hospital (ref) & na & 41,584 & na \\
\hline Health center/clinic/other & na & 44,756 & na \\
\hline \multicolumn{4}{|l|}{ Provider } \\
\hline Doctor (ref) & na & 46,897 & na \\
\hline Nurse-midwife & na & $38,689+$ & na \\
\hline Other & na & $30,191^{* *}$ & na \\
\hline \multicolumn{4}{|l|}{ WOMEN'S CHARACTERISTICS } \\
\hline \multicolumn{4}{|l|}{ Age } \\
\hline$\leq 19$ (ref) & 68,136 & 41,716 & 57,654 \\
\hline $20-29$ & 60,159 & 43,752 & 61,067 \\
\hline$\geq 30$ & $52,462^{* *}$ & 39,323 & 92,744 \\
\hline \multicolumn{4}{|l|}{ No. of living children } \\
\hline 0 (ref) & 77,038 & 46,758 & 67,668 \\
\hline $1-2$ & $53,413^{* * *}$ & 41,091 & 51,623 \\
\hline$\geq 3$ & $46,248^{* * *}$ & $37,676^{*}$ & 86,322 \\
\hline \multicolumn{4}{|l|}{ Marital status } \\
\hline Not married (ref) & 73,335 & 38,856 & 57,174 \\
\hline Married & $49,944^{* * *}$ & 43,845 & 75,101 \\
\hline \multicolumn{4}{|l|}{ Attending school } \\
\hline No (ref) & 51,479 & 43,232 & 72,418 \\
\hline Yes & $94,521^{* * *}$ & 38,482 & 50,042 \\
\hline \multicolumn{4}{|l|}{ Educational attainment } \\
\hline sprimary & $44,353^{* * *}$ & 40,432 & 58,458 \\
\hline >primary (ref) & 75,084 & 42,666 & 79,768 \\
\hline \multicolumn{4}{|l|}{ Residence } \\
\hline Rural (ref) & 52,248 & 39,376 & 73,879 \\
\hline Urban & $71,538^{* * *}$ & 45,844 & 59,817 \\
\hline \multicolumn{4}{|l|}{ Wealth } \\
\hline Poorest (ref) & 45,982 & 43,717 & 57,295 \\
\hline Middle & $61,055^{* * *}$ & 37,401 & 53,744 \\
\hline Wealthiest & $81,923^{* * *}$ & 46,821 & $116,447 \dagger$ \\
\hline
\end{tabular}

${ }^{* *} \mathrm{p}<.01 .{ }^{* * *} \mathrm{p}<.001 .+\mathrm{p}<.10$. Includes cost of postabortion care obtained prior to woman's arrival at facility. $\S$ Refers to the facility where the patient received postabortion care.Costs reported at the second interview are not given by facility characteristics, since these costs may have included expenses unrelated to the facility itself. Notes: $\mathrm{NGO}=$ nongovernmental organization. $\mathrm{na}=$ not applicable.

*We examined whether these measures of economic deterioration could be analyzed separately, but the number of respondents who had experienced each type was too small ( 21 had lost assets, 74 reported reduced consumption, 28 had incurred new debt and 40 reported change in wage work patterns). Preliminary checks revealed that only 20 women reported having had more than one of these experiences, indicating that people responded in different ways to the economic crisis imposed on them by the unsafe abortion. Thus, we combined these variables to create one measure.

†Since facilities across Uganda have the same policies with regard to when to admit women as inpatients and when to treat them as outpatients, this measure is likely to be unaffected by the policies of individual facilities. 


\begin{tabular}{|c|c|c|c|}
\hline \multirow[t]{2}{*}{ Measure } & \multicolumn{2}{|l|}{ First interview } & \multirow{2}{*}{$\begin{array}{l}\text { Second } \\
\text { interview } \\
\begin{array}{l}\text { Deterioration } \\
\text { in economic } \\
\text { circumstances } \\
(\mathrm{N}=420)\end{array}\end{array}$} \\
\hline & $\begin{array}{l}\text { Negative } \\
\text { consequences } \\
\text { for children } \neq \\
(\mathrm{N}=666)\end{array}$ & $\begin{array}{l}\text { Loss of } \\
\text { productivity } \\
(\mathrm{N}=1,047)\end{array}$ & \\
\hline All & 59.8 & 72.7 & 33.8 \\
\hline \multicolumn{4}{|c|}{$\begin{array}{l}\text { PRIMARY INDEPENDENT VARIABLES } \\
\text { No. of } \text { nights at facility }\end{array}$} \\
\hline 0 & $52.4^{*}$ & $60.8^{* * *}$ & $20.5^{* * *}$ \\
\hline 1 & 66.5 & 76.1 & 46.2 \\
\hline$\geq 2$ & 59.0 & 79.4 & 35.0 \\
\hline \multicolumn{4}{|c|}{ Postabortion care expenses } \\
\hline Low & $55.4 \dagger$ & 67.3 & 26.5 \\
\hline High & 61.3 & 76.5 & 38.7 \\
\hline \multicolumn{4}{|c|}{ WOMEN'S CHARACTERISTICS } \\
\hline Age & & & \\
\hline$\leq 19$ & $91.9^{* * *}$ & $67.5+$ & 27.6 \\
\hline $20-29$ & 62.4 & 73.4 & 35.6 \\
\hline$\geq 30$ & 50.8 & 76.3 & 36.7 \\
\hline \multicolumn{4}{|c|}{ No. of living children } \\
\hline 0 & na & $66.1^{* *}$ & $26.8 \dagger$ \\
\hline $1-2$ & $68.7^{* * *}$ & 76.2 & 34.6 \\
\hline$\geq 3$ & 49.1 & 77.2 & 40.1 \\
\hline \multicolumn{4}{|c|}{ Marital status } \\
\hline Not married & $51.0^{*}$ & $64.7^{* * *}$ & $26.3^{*}$ \\
\hline Married & 61.5 & 78.4 & 38.3 \\
\hline \multicolumn{4}{|c|}{ Attending school } \\
\hline No & 58.4 & $75.3^{* *}$ & $36.8^{*}$ \\
\hline Yes & 62.5 & 63.5 & 24.3 \\
\hline \multicolumn{4}{|c|}{ Educational attainment } \\
\hline sprimary & 60.1 & $77.0^{* *}$ & $38.7 \dagger$ \\
\hline >primary & 59.3 & 69.6 & 29.5 \\
\hline \multicolumn{4}{|l|}{ Residence } \\
\hline Rural & 59.9 & 73.5 & 32.4 \\
\hline Urban & 57.1 & 71.4 & 36.0 \\
\hline \multicolumn{4}{|l|}{ Wealth } \\
\hline Poorest & $64.0+$ & 74.0 & 35.8 \\
\hline Middle & 56.4 & 72.6 & 32.5 \\
\hline Wealthiest & 51.9 & 70.6 & 32.6 \\
\hline
\end{tabular}

${ }^{*} p<.05 .{ }^{* *} p<.01 .{ }^{* * *} p<.001 .+p<.10 . \neq$ Among respondents with children. Notes: Results of significance tests refer to differences across subgroups. na $=$ not applicable.

These amounts were summed to determine the total outof-pocket expenses related to obtaining postabortion care. The second variable concerned the amount of money

\footnotetext{
* In the first survey, only 74 of the 666 respondents with children fell into the quintile with the highest abortion expenses, and in the follow-up sample 89 of the 420 women belonged to the quintile that had the highest postabortion care expenses. As a result, regression estimates were unstable when we used three-category variables for both outcomes. Therefore, for consistency, we used a binary variable for both types of expenses.

tSince some of the household possessions that were used to calculate wealth index scores were assets that respondents might sell if their economic circumstances deteriorated, we did not include wealth as a control in models for the latter outcome, to avoid endogeneity.

fWe present all costs in 2012 Ugandan shillings and U.S. dollars, using the average exchange rate for this period (2,625 shillings per dollar).
}

women had spent to obtain the unsafe abortion and for any treatment they received for complications of abortion (spontaneous or induced) prior to arriving at the facility. The question for the latter measure was worded in such a way that respondents could provide an estimate of their abortion-related expenses even if they did not wish to admit having attempted to terminate their pregnancy.

We used both variables in our analysis. For each, we created binary variables by dividing expenses into quintiles and then combining the first and second quintiles (lower expenses) and the third through fifth quintiles (higher expenses). We were unable to create multicategory variables in most models owing to problems with cell sizes. *

\section{Controls}

-Wealth index. To group women by economic status, we used a household-based wealth index variable analogous to the wealth index provided in Demographic and Health Survey data. ${ }^{20-22}$ To create this index, we performed a factor analysis that included the following variables: the household's source of water; the quality of the dwelling's roof; the type of toilet, type of stove, and number of rooms in the house; and the family's ownership of various consumer goods, livestock and their home. These variables were analyzed using principal components factor analysis, and the first factor loading was used to create the index. ${ }^{20}$

The factor loading was then divided into quintiles, and we classified women into three groups: wealthiest (richest quintile), intermediate (next two quintiles), and poorest (final two quintiles). ${ }^{\dagger}$ No association was apparent between household wealth and the type of facility (public or private) at which women received postabortion care (Web Appendix Table 2).

- Other measures. The other control variables in our models were age, number of living children, marital status, whether the respondent was attending school, education level and residence (urban or rural). Information on these characteristics was obtained directly from women at the time of the surveys.

Data were analyzed in SAS using a combination of univariate and multivariate techniques, such as descriptive statistics and logistic regressions. We used t tests and chisquare tests to assess statistical significance.

\section{RESULTS}

\section{Descriptive}

- Sample. In both surveys, about half of respondents were aged 20-29 (Appendix Table 1, page 182). Nearly twothirds had at least one child. Seven in 10 were currently or formerly married, and six in 10 lived in a rural area. A substantial minority (43-48\%) required at least a two-night stay in a facility to treat their postabortion complications.

- Out-of-pocket expenses. Respondents who likely had had an unsafe abortion had paid an average of 59,600 shillings (US\$23) in out-of-pocket expenses for the procedure, for the treatment of complications prior to arriving at the facility, or both (Table 1, page 177 ). ${ }^{\ddagger}$ In addition, on 
average, women paid 41,800 shillings (US\$16) in out-ofpocket costs for treatment of postabortion complications at the health facility where they were initially interviewed; at follow-up, a couple of months after the first interview, women reported having paid an additional 26,700 shillings (US\$10) for medical expenses incurred between the first and second interviews. The average total out-of-pocket expenditure per woman was 128,000 shillings (US\$49not shown).

The amount paid to obtain an unsafe abortion was higher among women who were younger than 20 (68,100 shillings), childless (77,000), unmarried $(73,300)$, attending school $(94,500)$, residing in urban areas $(71,500)$ or in the wealthiest group (81,900 shillings) than among women in the respective reference groups.

Not surprisingly, the expenses women incurred for postabortion care were higher among women who had spent two or more nights in the health facility $(58,900$ shillings) than among women with shorter stays (28,90029,500), as severe complications that require a longer stay at the facility are likely to lead to higher expenses. Facility and provider characteristics were also strongly associated with the level of expenses incurred. Women who had received postabortion care at private or nonprofit facilities incurred higher expenses than did women treated at public facilities (153,000 vs. 32,300 shillings), and women who were treated by doctors paid more than did women who received care from providers other than doctors or nursemidwives (46,900 vs. 30,200). Furthermore, women who did not have any children incurred higher postabortion care expenses than did women with three or more children (46,800 vs. 37,700).

No subgroup differences were observed at the follow-up interviews for postabortion care expenses.

- Social and economic outcomes. At the first interview, 60\% of the 666 women who had children reported that their children were eating less, were unable to attend school or both as a result of the abortion (Table 2). In addition, $73 \%$ of the women who likely had had an induced abortion stated that they or someone else in their household were already experiencing some loss of productivity. During the follow-up interviews, 34\% of the 420 women who likely had had an induced abortion reported that they had experienced an economic impact from their abortion complications.

Most of our independent variables were associated with one or more negative consequences. Overall, higher proportions of women who had more serious complications (i.e., had spent a night or more in a health facility) than those with less serious complications reported having experienced negative consequences-their children had suffered, they or someone in their household had lost productive employment or their economic circumstances had deteriorated. The proportion of women who reported that their children had suffered negative consequence declined with increasing age, from 92\% among teenage respondents to 62\% among 20-29-year-olds and 51\% among
TABLE 3. Odds ratios (and standard errors) from regression analyses examining the likelihood that women reported that their unsafe abortion resulted in negative consequences for their children or loss of productivity

Measure

Odds ratio

\begin{tabular}{|c|c|c|}
\hline & $\begin{array}{l}\text { Negative } \\
\text { consequences } \\
\text { for children¥ }\end{array}$ & $\begin{array}{l}\text { Loss of } \\
\text { productivity }\end{array}$ \\
\hline \multicolumn{3}{|c|}{ PRIMARY INDEPENDENT VARIABLES } \\
\hline \multicolumn{3}{|c|}{ No. of nights at facility } \\
\hline 0 (ref) & 1.00 & 1.00 \\
\hline 1 & $1.76(0.250)^{*}$ & $2.20(0.203)^{* * *}$ \\
\hline$\geq 2$ & $1.63(0.221)^{*}$ & $2.39(0.182)^{* * *}$ \\
\hline \multicolumn{3}{|l|}{ Postabortion care expenses } \\
\hline Low (ref) & 1.00 & 1.00 \\
\hline High & $0.91(0.187)$ & $1.16(0.167)$ \\
\hline \multicolumn{3}{|l|}{ WOMEN'S CHARACTERISTICS } \\
\hline Age & & \\
\hline$\leq 19$ (ref) & 1.00 & 1.00 \\
\hline $20-29$ & $0.18(0.627)^{* *}$ & $1.00(0.219)$ \\
\hline$\geq 30$ & $0.17(0.650)^{* *}$ & $0.97(0.320)$ \\
\hline \multicolumn{3}{|l|}{ No. of living children§ } \\
\hline 0 (ref) & na & 1.00 \\
\hline $1-2$ (ref) & 1.00 & $1.50(0.232) \dagger$ \\
\hline$\geq 3$ & $0.39(0.228)^{* * *}$ & $1.42(0.301)$ \\
\hline \multicolumn{3}{|l|}{ Marital status } \\
\hline Not married (ref) & 1.00 & 1.00 \\
\hline Married & $2.24(0.226)^{* * *}$ & $1.58(0.193)^{*}$ \\
\hline \multicolumn{3}{|l|}{ Attending school } \\
\hline No (ref) & 1.00 & 1.00 \\
\hline Yes & $0.70(0.791)$ & $0.97(0.253)$ \\
\hline \multicolumn{3}{|l|}{ Educational attainment } \\
\hline sprimary (ref) & 1.00 & 1.00 \\
\hline$>$ primary but not $>$ secondary & $1.19(0.217)$ & $0.89(0.185)$ \\
\hline >secondary & $0.79(0.365)$ & $0.72(0.286)$ \\
\hline \multicolumn{3}{|l|}{ Residence } \\
\hline Rural (ref) & 1.00 & 1.00 \\
\hline Urban & $1.24(0.221)$ & $0.99(0.183)$ \\
\hline \multicolumn{3}{|l|}{ Wealth } \\
\hline Poorest (ref) & 1.00 & 1.00 \\
\hline Middle & $0.47(0.233)^{* *}$ & $1.12(0.199)$ \\
\hline Wealthiest & $0.40(0.310)^{* *}$ & $1.17(0.248)$ \\
\hline Intercept & $1.978(0.675)^{* *}$ & $-0.038(0.293)$ \\
\hline
\end{tabular}

${ }^{*} \mathrm{p}<.05 .{ }^{* *} \mathrm{p}<.01 .{ }^{* * *} \mathrm{p}<.001 .+\mathrm{p}<.10$. $\neq$ Among respondents with children. §Reference category is 0 for loss of productivity and 1-2 for negative consequences for children. Notes: Missing values were dropped using listwise deletion, resulting in sample sizes of 568 for negative consequences for children and 919 for loss of productivity. na=not applicable.

older women. Women with one or two living children were more likely than women of higher parity to report that their children had been negatively affected (69\% vs. $49 \%$ ); however, those with at least one child were more likely than childless women to have suffered some loss of productivity (76-77\% vs. $66 \%$ ). The proportion of women who reported that they, their children, or someone in their household had suffered negative consequences was consistently higher among married women than among unmarried women.

Women who were not attending school were more likely than those who were to report loss of productivity (75\% 
vs. 64\%) and deterioration of economic circumstances ( $37 \%$ vs. $24 \%$ ), and those with no more than a primary education were more likely than better-educated women to report lost productivity (77\% vs. $70 \%$ ).

\section{Multivariate Analyses}

- Negative consequences for children. ${ }^{*}$ The odds that a woman's children had already experienced negative consequences-had had less food than usual, had missed school or both-at the time she was being treated for abortion complications were higher among women who had spent a night or more at a health facility than among women who had not had an overnight stay (odds ratios, 1.6-1.8; Table 3 , page 179). The likelihood of negative consequences was substantially lower among children of women aged 20 or older than among those of teenage respondents (0.2 for both older age-groups), and lower among children of women with at least three living offspring than among those of lower-parity women (0.4). Children of married women had more than twice the odds of having suffered negative consequences than did children of unmarried women (2.2). Finally, and not unexpectedly, children of women in the two wealthiest groups were less likely than those of the poorest respondents to have had any negative consequences as a result of their mother's postabortion

\begin{tabular}{|c|c|}
\hline Measure & Odds ratio \\
\hline \multicolumn{2}{|c|}{ PRIMARY INDEPENDENT VARIABLES } \\
\hline 0 (ref) & 1.00 \\
\hline 1 & $2.82(0.325)^{* *}$ \\
\hline$\geq 2$ & $1.71(0.297) \dagger$ \\
\hline \multicolumn{2}{|l|}{ Postabortion care expenses } \\
\hline Low (ref) & 1.00 \\
\hline High & $1.63(0.239)^{*}$ \\
\hline \multicolumn{2}{|l|}{ WOMEN'S CHARACTERISTICS } \\
\hline \multicolumn{2}{|l|}{ Age } \\
\hline$\leq 19$ & $1.01(0.422)$ \\
\hline $20-29$ & $1.15(0.299)$ \\
\hline$\geq 30$ (ref) & 1.00 \\
\hline \multicolumn{2}{|l|}{ No. of living children } \\
\hline 0 (ref) & 1.00 \\
\hline $1-2$ & $1.16(0.334)$ \\
\hline$\geq 3$ & $1.42(0.393)$ \\
\hline \multicolumn{2}{|l|}{ Marital status } \\
\hline Not married (ref) & 1.00 \\
\hline Married & $1.31(0.276)$ \\
\hline \multicolumn{2}{|l|}{ Educational attainment } \\
\hline$\leq$ primary & $1.41(0.243)$ \\
\hline$>$ primary (ref) & 1.00 \\
\hline \multicolumn{2}{|l|}{ Residence } \\
\hline Rural (ref) & 1.00 \\
\hline Urban & $1.42(0.238)$ \\
\hline Intercept (standard deviation) & $-2.222(0.505)$ \\
\hline
\end{tabular}

complications (0.4-0.5).

- Loss of productivity. Only two characteristics were associated with the respondent or other household members having experienced reduced productivity (inability to work, to earn or both) because of the respondent's abortion-related morbidity. The odds of productivity loss among women who had spent one or more nights in a health facility (and hence probably had relatively severe complications) were more than twice those of women who had been treated as outpatients (odds ratios, 2.2-2.4). In addition, loss of productivity was more common in households of married women than in those of unmarried women (1.6).

- Deterioration in economic circumstances. ${ }^{\dagger}$ Among women who were re-interviewed 2-3 months after receiving postabortion care, two characteristics were associated with deterioration in their economic circumstances-that is, with whether they and their family had lost economic assets, incurred debt, lowered their consumption, or had to work more or give up their jobs in response to their illness (Table 4). Women who had spent one night at the health facility had higher odds of experiencing economic deterioration than did women who had not had an overnight stay (odds ratio, 2.8) and women who had incurred higher postabortion care expenses (i.e., those in the highest three quintiles) were more likely than those with lower expenses to have seen their economic circumstances worsen (1.6).

\section{DISCUSSION}

Because of fear of legal consequences and strong social stigma, the vast majority of abortions in Uganda occur in secrecy or under unsafe conditions. Although research has helped raise awareness of the impact of unsafe abortion on maternal health and survival, as well as of its financial costs to the country's health sector, data on the economic impact of unsafe abortions on women and their households are generally unavailable. Such information is lacking not only for Uganda but for the rest of the developing world. To our knowledge, the present study represents the first large-scale, evidence-based attempt to bridge this information gap, as no previous study has combined abortion and health data with information on economic outcomes among women who received treatment for postabortion complications.

Because women were reluctant to disclose that they had obtained an induced abortion, we used an algorithm developed by the WHO to classify our respondents according to whether they certainly, probably or possibly had induced an abortion, or whether the abortion had been spontaneous. In comparing the socioeconomic and demographic characteristics of the two sets of respondents, we found

*This model was restricted to respondents who reported having living children.

†This model does not control for whether the respondent was attend ing school, because this variable was moderately correlated with marital status in the follow-up sample (coefficient, -0.58 ); this resulted in multicollinearity and a poor model fit in the regression. 
that the results were in the expected direction: Adolescents, students and unmarried women were more likely than older women, nonstudents and married women, respectively, to have had an induced abortion. These findings, which are consistent with previous research indicating that levels of unsafe abortion are disproportionately high among adolescents in Africa, ${ }^{23,24}$ suggest that women in these groups may have had out-of-wedlock pregnancies and been seeking an abortion because of the stigma associated with such pregnancies. Not unexpectedly, women of higher socioeconomic status were more likely than other women to have had an induced rather than a spontaneous abortion; since women of higher socioeconomic status generally have lower desired fertility than other women, they may, in a context of high unmet need, be more likely than others to have an abortion to space or limit childbearing. ${ }^{25,26}$

The study shows that Ugandan women and their households spend a substantial amount of money on unsafe abortions and postabortion care. These expenditures are especially significant, given that Uganda has one of the lowest per capita incomes in the world and that a substantial proportion of the population is poor.* It is therefore not surprising that the vast majority of women treated for postabortion complications reported that their unsafe abortion had had adverse effects on the well-being of their children, on their own productivity or that of others in their household, or on the economic situation of their households. Each of these consequences is troublesome on its own; the impact of a combination of them could be even more significant in magnitude and duration.

The factors associated with the adverse impact of having an unsafe abortion varied by subgroup. For example, the children of respondents with severe complications were more likely than those of women with less severe complications to suffer negative effects. Severe complications also led to lower productivity for respondents or other household members. Moreover, as expected, poorer women were especially likely to report negative economic and social consequences of abortion complications; their children were more likely than the children of wealthier women to have had less to eat than before or to have missed school.

Further ramifications of the deterioration in economic circumstances were revealed in the follow-up survey. Women who required a night's stay at a facility, and those who had incurred greater expenses for postabortion care, had elevated odds of having suffered economic consequences, such as reduced consumption or changes in work patterns, due to disabilities or additional responsibilities at home.

This deterioration of households' economic health indicates that unsafe abortion burdens not only the country's health system, ${ }^{12}$ but also women and their families. Moreover, poor women and their households disproportionately bear the economic and social burden. Other research has shown that among Ugandan women who obtain abortions, poor women are more likely than others to have unsafe procedures and experience complications, and less likely to get the care they need. ${ }^{3}$ They are therefore more likely than other women to experience negative consequences.

Our analyses also showed that women with fewer children were more likely to experience negative consequences than were their peers who had more children. It may be low-parity women invest more in their children than other women do, and as a result experience greater economic shocks from complications of unsafe abortion. It is also possible that when women have many children (about 30\% of participants had three or more), the older children are able to take care of their younger siblings, thereby mitigating the effect of their mother's morbidity. Furthermore, our finding that women with no children incurred higher postabortion care expenses than did women with three or more children may be an indication that they sought services from private providers (who charge more than public-sector providers) to ensure confidentiality; these and other women for whom abortion is more severely stigmatized may be willing to pay extra to ensure their privacy.

In addition, married women were more likely than unmarried women to have experienced negative consequences. Some evidence suggests that women do not let their partners know about abortions, and that the greatest secrecy is exercised within marriage. ${ }^{27}$ When husbands find out about an abortion, they may abandon their wife because they suspect infidelity. ${ }^{27,28}$ These circumstances may force married women to suffer the consequences of their unsafe abortions in silence and in secret. Abortion is viewed more leniently in Uganda if the woman is unmarried, and especially if she is a schoolgirl; ${ }^{27}$ unmarried women, who tend to be younger and are often childless, may also have fewer familial obligations than other women, which may reduce the impact of abortion morbidity on their lives.

Our study is not without limitations. The analysis of economic impact is dependent on the women's retrospective assessments of changes in their circumstances. Such assessments are subject to accuracy of recall; however, we relied on them for our analyses because we did not have any information on women's circumstances prior to their abortion attempt.

In addition, we focused on women who had presented at health facilities to receive care for abortion complications, and although an estimated $60 \%$ of women with such complications present at facilities to receive care, the remaining $40 \%$ do not. ${ }^{3}$ It would be reasonable to expect that the remaining women and their households also suffer some negative impact as a result of abortion-related morbidity.

Another potential limitation is that although the WHO algorithm is very useful, it may not be perfect, and some of

*Per capita income was US\$510 in 2011, and 38\% of the population lived on US\$1.25 per day in 2009 (source: World Bank, Poverty and equity: Uganda, no date, <http://povertydata.worldbank.org/poverty/country/ UGA $>$ accessed May 28, 2013). 


\begin{tabular}{|c|c|c|}
\hline Measure & $\begin{array}{l}\text { First } \\
\text { interview } \\
(\mathrm{N}=1,047)\end{array}$ & $\begin{array}{l}\text { Second } \\
\text { interview } \\
(\mathrm{N}=420)\end{array}$ \\
\hline \multicolumn{3}{|l|}{ Age } \\
\hline$\leq 19$ & 23.6 & 23.6 \\
\hline $20-29$ & 50.1 & 50.1 \\
\hline$\geq 30$ & 26.3 & 26.3 \\
\hline \multicolumn{3}{|c|}{ No. of living children } \\
\hline 0 & 36.1 & 34.1 \\
\hline $1-2$ & 32.7 & 31.9 \\
\hline$\geq 3$ & 31.3 & 34.1 \\
\hline \multicolumn{3}{|l|}{ Marital status } \\
\hline Never married & 31.1 & 28.8 \\
\hline Ever married & 68.9 & 71.2 \\
\hline \multicolumn{3}{|c|}{ Attending school } \\
\hline No & 82.5 & 82.8 \\
\hline Yes & 17.5 & 17.2 \\
\hline \multicolumn{3}{|c|}{ Educational attainment } \\
\hline sprimary & 46.4 & 48.0 \\
\hline Middle & 43.3 & 43.5 \\
\hline$\geq$ secondary & 10.3 & 8.5 \\
\hline \multicolumn{3}{|l|}{ Residence } \\
\hline Rural & 62.0 & 61.7 \\
\hline Urban & 38.0 & 38.3 \\
\hline \multicolumn{3}{|l|}{ Wealth } \\
\hline Poorest & 38.9 & 39.3 \\
\hline Middle & 40.0 & 39.5 \\
\hline Wealthiest & 21.1 & 21.2 \\
\hline \multicolumn{3}{|l|}{ No. of nights } \\
\hline 0 & 30.6 & 26.7 \\
\hline 1 & 26.5 & 24.8 \\
\hline$\geq 2$ & 42.8 & 48.4 \\
\hline Total & 100.0 & 100.0 \\
\hline
\end{tabular}

Notes: Missing values are not shown; for individual variables, the proportion of missing responses ranged from $0 \%$ to $6 \%$. Percentages may not total $100 \%$ because of rounding.

our classifications may have been inaccurate. ${ }^{*}$ Finally, future studies of this kind would benefit from having a larger sample size for both the initial and follow-up surveys. Inclusion of a greater number of women who had miscarried

\footnotetext{
*If spontaneous abortions had been miscategorized by the $\mathrm{WHO}$ algorithm as induced abortions (most likely as "possibly induced"), the average severity of complications of induced abortions-and the magnitude of impact of these complications on health and economic outcomes-might have been reduced. The opposite would have occurred if some cases of less severe complications of induced abortion had been classified as complications of spontaneous abortions. Because a very high proportion (36\%) of patients in this study were classified as certainly having had induced abortions and an additional $14 \%$ as probably having had induced abortions, while only $28 \%$ were classified as possibly having had induced abortions, the likelihood that either of these biases occurred is smaller than it was in other studies that had a much higher proportion of cases in the "possibly induced" category.

†A potential problem with the survey design is the possibility of selection bias in the follow-up sample. However, because the distribution of respondents' demographic characteristics (age, parity, wealth, marital status, residence and education level) was almost identical across the two waves, we are reasonably certain that our results were not influenced by selection bias.
}

would also be desirable, to allow comparison of their characteristics with those of women with induced abortions. ${ }^{\dagger}$

Despite these drawbacks, our findings call for programs and policies to help reduce recourse to unsafe abortion and diminish the consequences of such abortions, in particular through the provision of abortion services to the full extent of the law. The higher cost paid by women who have no children suggests there is great need to sensitize staff at public-sector facilities regarding the right of childless women to receive nonjudgmental services. In addition, a concerted effort is needed to reduce the costs associated with postabortion care.

Because the root cause of most abortions is unintended pregnancy, women's access to effective contraceptives needs to be improved. This is particularly important in light of the fact that the cost of an unsafe abortion is almost as high as the cost of the treatment. It would be much more cost-effective for women to have access to cheaper contraceptives than to have to undergo costly and unsafe procedures. Additionally, accurate information on availability of contraceptive services needs to be disseminated; greater efforts are needed to ensure that poor women in particular are aware of and have relatively easy access to these services. Finally, our study also illustrates a need for further research on this subject in Uganda and other developing countries to improve understanding of the impact of unsafe abortion and associated morbidity on the economic and social lives of women and their households.

\section{REFERENCES}

1. Singh $\mathrm{S}$ et al., The incidence of induced abortion in Uganda, International Family Planning Perspectives, 2005, 31(4):183-191.

2. Sedgh $G$ et al., Induced abortion: incidence and trends worldwide from 1995 to 2008, Lancet, 2012, 379(9816):625-632.

3. Singh S et al., Unintended Pregnancy and Induced Abortion in Uganda: Causes and Consequences, New York: Guttmacher Institute, 2006.

4. Mirembe FM and Okong P, Risk factors associated with maternal mortality in three Kampala hospitals, unpublished report, Kampala, Uganda: Makerere University, 1995.

5. Government of Uganda Ministry of Health, Health Sector Strategic Plan III: 2010/11-2014/15, Kampala, Uganda: Ministry of Health, 2010

6. Uganda Bureau of Statistics, ICF International and Measure DHS, Uganda Demographic and Health Survey 2011, Calverton, MD, USA: Measure DHS and ICF International, 2012.

7. World Health Organization (WHO) et al., Trends in Maternal Mortality: 1990 to 2010, Geneva: WHO, 2012

8. Ahman E and Shah I, Unsafe Abortion: Global and Regional Estimates of the Incidence of Unsafe Abortion and Associated Mortality in 2003, Geneva: WHO, 2007.

9. Grimes DA et al., Unsafe abortion: the preventable pandemic, Lancet, 2006, 368(9550):1908-1919.

10. Vlassoff $\mathrm{M}$ et al., Economic impact of unsafe abortion-related mor bidity and mortality: evidence and estimation challenges, IDS Research Report, Brighton, UK: Institute of Development Studies, University of Sussex, 2008, No. 59.

11. Bankole A et al., Estimating the cost of post-abortion care in Nigeria: a case study, in: Lule E, Singh S and Chowdhury SA, eds., Fertility Regulation Behaviors and Their Costs: Contraception and Unintended Pregnancies in Africa and Eastern Europe \& Central Asia, Washington, DC: World Bank, 2007, pp. 65-92.

12. Vlassoff $\mathrm{M}$ et al., The health system cost of post-abortion care in 
Uganda, Health Policy and Planning, 2012, doi: 10.1093/heapol/czs133.

13. Henshaw SK et al., Severity and cost of unsafe abortion complications treated in Nigerian hospitals, International Family Planning Perspectives, 2008, 34(1):40-50

14. Babigumira JB et al., Estimating the costs of induced abortion in Uganda: a model-based analysis, BMC Public Health, 2011, Vol. 11, Art. 904, <http://www.biomedcentral.com/1471-2458/11/904>, accessed Aug. 8, 2012

15. Potdar R, Fetters T and Phirun L, Initial loss of productive days and income among women seeking induced abortion in Cambodia, Journal of Midwifery \& Women's Health, 2008, 53(2):123-129.

16. Narkavonnakit T and Bennett T, Health consequences of induced abortion in rural Northeast Thailand, Studies in Family Planning, 1981, 12(2):58-65.

17. Woog V, Singh S and Bankole A, A review of the evidence of the cost of post-abortion care in Africa, in: Lule E, Singh S and Chowdhury SA, eds., Fertility Regulation Behaviors and Their Costs: Contraception and Unintended Pregnancies in Africa and Eastern Europe \& Central Asia, Washington, DC: World Bank, 2007, pp. 40-64.

18. Guttmacher Institute, Pilot study of the economic and social costs of unsafe abortion in Ethiopia, Mexico and Pakistan: design, instruments and lessons learned, unpublished report, New York: Guttmacher Institute, 2008

19. Figà-Talamanca I et al., Illegal abortion: an attempt to assess its cost to the health services and its incidence in the community, International Journal of Health Services, 1986, 16(3):375-389.

20. Filmer D and Pritchett LH, Estimating wealth effects without expenditure data-or tears: an application to educational enrollments in states of India, Demography, 2001, 38(1):115-132.

21. Rutstein SO and Johnson K, The DHS Wealth Index, Calverton, MD, USA: ORC Macro, 2004.

22. Filmer D and Pritchett L, The effect of household wealth on educational attainment: evidence from 35 countries, Population and Development Review, 1999, 25(1):85-120.

23. Salter C, Johnston HB and Hengen N, Care for postabortion complications: saving women's lives, Population Reports, 1997, Series L, No. 10

24. Shah I and Ahman E, Unsafe abortion in 2008: global and regional levels and trends, Reproductive Health Matters, 2010, 18(36):90-101.

25. Kravdal $\varnothing$, Education and fertility in Sub-Saharan Africa: individual and community effects, Demography, 2002, 39(2):233-250.

26. Mote CV, Otupiri E and Hindin MJ, Factors associated with in duced abortion among women in Hohoe, Ghana, African Journal of Reproductive Health, 2010, 14(4):110-116.

27. Moore AM, Jagwe-Wadda G and Bankole A, Men's attitudes about abortion in Uganda, Journal of Biosocial Science, 2011, 43(1):31-45.

28. Blanc AK et al., Negotiating Reproductive Outcomes in Uganda, Calverton, MD, USA and Kampala, Uganda: Macro International and Institute of Statistics and Applied Economics, 1996.

\section{RESUMEN}

Contexto: Aunque Uganda tiene una ley de aborto restrictiva, en el país se dan un gran número de abortos realizados bajo condiciones de riesgo. Sin embargo, no existen datos sobre el impacto económico de las complicaciones postaborto para las mujeres y sus familias.

Métodos: Con el propósito de estimar las consecuencias económicas del aborto inseguro y los tratamientos subsiguientes, se utilizaron los datos de una encuesta realizada entre los años 2011 y 2012 a 1.338 mujeres que habian recibido atención postaborto en 27 instituciones de salud ugandesas. Así se obtuvo información sobre los costos de tratamiento y sobre el impacto de las complicaciones del aborto en los niños y niñas de la familia, en la productividad de la persona entrevistada y de otros miembros de la familia, y en los cambios que afectaron a su situación económica.

Resultados: La mayoría de las mujeres reportaron que el aborto inseguro había causado uno o más efectos adversos en sus vidas, incluyendo la falta de productividad (73\%), consecuencias negativas para sus hijos (60\%) y un deterioro de su situación económica (34\%). La probabilidad de haber sufrido alguna de estas tres consecuencias es mayor entre las mujeres que pasaron una o más noches recibiendo atención postaborto en un centro que entre aquellas que no tuvieron que quedarse (cociente de probabilidades, 1.6-2.8). La probabilidad de reportar un deterioro de su situación económica es mayor entre las mujeres que tuvieron que afrontar mayores gastos de atención postaborto que entre aquellas que tuvieron que afrontar gastos más bajos (1.6). La probabilidad de reportar que sus hijos habian sufrido consecuencias negativas es menor entre las mujeres más ricas que entre las más pobres (0.4-0.5).

Conclusiones: Las complicaciones del aborto inseguro y el gasto de tratarlas tienen un impacto sustancial para las mujeres ugandesas y sus familias. Hay una necesidad urgente de implementar estrategias, como expandir el acceso a los anticonceptivos para prevenir los embarazos no planeados, con el fin de reducir el número de procedimientos inseguros.

\section{RÉSUMÉ}

Contexte: Malgré la législation restrictive de l'avortement en Ouganda, les procédures clandestines, pratiquées dans des conditions dangereuses, sont fréquentes. Peu de données sont cependant disponibles concernant l'impact économique, sur les femmes et les ménages, des complications après avortement. Méthodes: Les données d'une enquête réalisée en 2011-2012 auprès de 1.338 femmes ayant reçu des soins après avortement dans 27 centres de santé ougandais ont servi à évaluer les conséquences économiques de l'avortement non médicalisé et du traitement de ses complications. Des données ont été obtenues sur les coûts du traitement et sur l'impact des complications de l'avortement sur les enfants du ménage, sur la productivité de la répondante et des autres membres du ménage et sur les changements survenus au niveau de leurs circonstances économiques.

Résultats: La plupart des femmes ont déclaré que leur avortement non médicalisé avait eu au moins un effet indésirable, tel que perte de productivité (73\%), conséquences négatives pour les enfants (60\%) et détérioration des circonstances économiques (34\%). Les femmes qui avaient passé au moins une nuit dans un établissement prestataire de soins après avortement se sont révélées plus susceptibles d'avoir subi ces trois conséquences (OR, 1,6-2,8) et celles qui avaient encouru de plus grands frais de soins après avortement, plus susceptibles de déclarer une détérioration de leurs circonstances économiques $(1,6)$. Les femmes plus riches se sont avérées moins susceptibles que les plus pauvres de faire état de conséquences négatives pour leurs enfants $(0,4-0,5)$.

Conclusions: L'impact des complications de l'avortement non médicalisé et les frais encourus pour leur traitement sont considérables pour les femmes ougandaises et leur ménage. Il 
existe un besoin urgent de stratégies de réduction du nombre de procédures non médicalisées, par l'élargissement de l'accès à la contraception pour éviter les grossesses non planifiées notamment.

\section{APPENDIX A: Laws and Policies on Abortion in Uganda}

The laws and policies on abortion in Uganda are unclear and inconsistent, making interpretation difficult and resulting in conflicting views about the indications under which abortion is permitted. Under the Ugandan Penal Code of 1950, abortion is generally prohibited, except when a woman's life is in danger. Court cases have interpreted this life exception as encompassing an exception to preserve the pregnant woman's mental and physical health. The Ministry of Health's National Policy Guidelines and Service Standards for Sexual and Reproductive Health and Rights specify that a woman may receive services for termination of pregnancy in certain circumstances, which include: instances in which a severe illness threatens the health of the woman; those in which a woman has become pregnant as a result of rape or incest; and those in which the fetus has severe abnormalities. These guidelines, however, have not been widely disseminated to the medical community.

For more information:

- United Nations Population Division, World Population Policies 2009 Database, New York: United Nations, 2010, http://www.un.org/en/development/desa/population/ publications/database/worldPopulationPolicies_2009. shtml.

- 10 Key points about Uganda's laws and policies on termination of pregnancy, http://reproductiverights. org/sites/crr.civicactions.net/files/documents/crr uganda_10keypoints_v5.pdf.

\section{Acknowledgments}

This research was supported by a grant from the Swedish International Development Cooperation Agency, the Dutch Ministry of Foreign Affairs and the David \& Lucile Packard Foundation. An earlier version of this article was presented at the 2013 Annual Meeting of the Population Association of America and the International Union for the Scientific Study of Populations. We would like to thank Suzette Audam, Alyssa Browne, Rubina Hussain, Richard Kibombo, Charles Kiggundu, Isaac Maddow-Zimet, Florence Mirembe and Elena Prada for their helpful comments and contributions to this article.

Author contact: asundaram@guttmacher.org 